\title{
The design and manufacture of the dust removal device for households with coal-fired stove
}

\author{
Xiaohan Qi \\ School of electric power engineering, North China Electric Power University, Baoding 071000, \\ China. \\ 2543090766@qq.com
}

Keywords: coal combustion, stove,

\begin{abstract}
The burning of coals in urban and rural areas in northern China is inevitable, and many of them have not taken any measures to reduce the dust and smoke. The burning of coal in urban and rural areas in northern China is inevitable, and many of them have not taken any measures to reduce the dust and smoke. The cumulative emissions of sooth have big impact on the quality of the air. Our project is to design and manufacture a kind of dust reduction which is installed inside the flue. Through the comparison of the combustion test, it is proved that the purpose of reducing soot emission is realizable. The device is mainly divided into two parts, one is activated carbon barrel and the other is sliding lid box. The principle of the device design is easy to use which is suitable for installation and cost is not high. It can have a certain effect on the environment.
\end{abstract}

\section{Introduction}

In northern urban and rural areas, coal combustion is an inevitable problem ${ }^{[1]}$. Regardless of the individual heating and one stove with multifunction, no matter size, no matter the use of energy saving stoves or all kinds of ordinary stoves, soot emissions, which of them without any measures of smoke dust drop. In many places, the cumulative emissions which impact the quality of the air are also very large and there are many aspects of the management of the concept and management issues, which is the difficulty of environmental protection.

The innovate project is to design and manufacture a kind of installation in the chimney within the dust emission reduction device, which for villages, towns and villages of household, households with scattered coal-fired stove. The goal is to reduce carbon through the selection and comparison of adsorption materials and processes. The design required it is easy to operate and it costs lower which is suitable for rural residents to use.

\section{The design and manufacture of equipment}

The overall design. Product divides into two parts, the upper for the activated carbon ${ }^{[2]}$ barrel which is placed inside the flue and contained granular activated carbon. According to the design of the structure of carbon barrel, flue gas in carbon barrel can be fully contacted with activated carbon which has a better absorption effect on flue gas. At the bottom for sliding lid box which contains filter net which fixed with the spring and tableting. The filter net attached with Cao powder which completely obstructing particulate pollutants as well as $\mathrm{SO}_{2}$. Box adopts slide structure which is easy to periodic replacement and cleaning. Overlying the two parts, it has big effect. From bottom to top, flue gas pass through the sliding lid box the activated carbon barrel in turn which absorbs the big smoke, acid gases, small particles which realize better dust removal effect.

The design of activated carbon barrel. The carbon barrel is arranged inside the chimney. The environment has high temperature, high acidity characters. On account of these characters, we select materials that conform to the above properties. In order to make the flue gas fully contacts with activated carbon, we make unique design for both the top and bottom surfaces. In order to ensure the barrel can both filled with activated carbon granule and can make the flue gas through it, we adopted sieve tube design as the following figture1. 

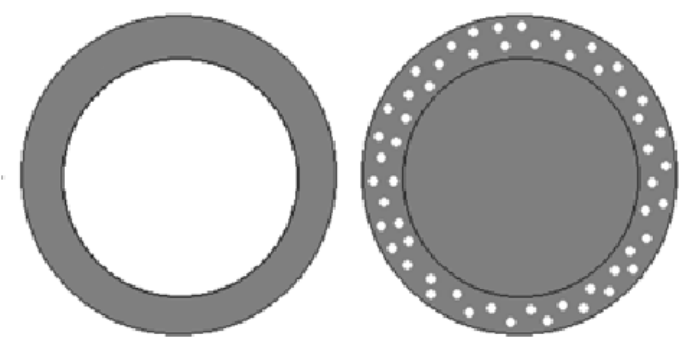

Fig.1 The top and bottom surfaces

Flue gas flows through the carbon barrel as the following picture:

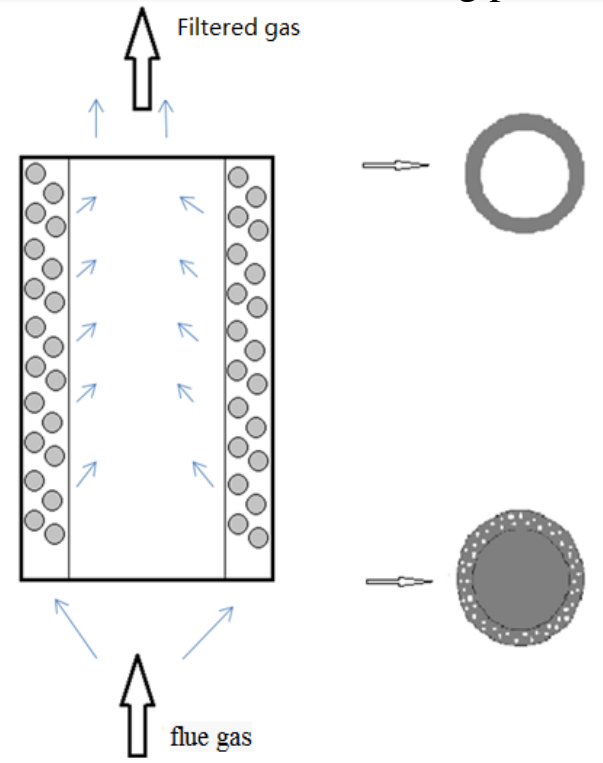

Fig.2 Function sketch maps

The design of sliding lid box. Sliding lid box is arranged in the chimney connection point and is used as a part of the chimney. So the air tightness requirement is relatively high. In addition, the environment is of high temperature and high acidity characteristics. On account of these conditions, the materials should meet all the requirements. Specific structure is shown as below:

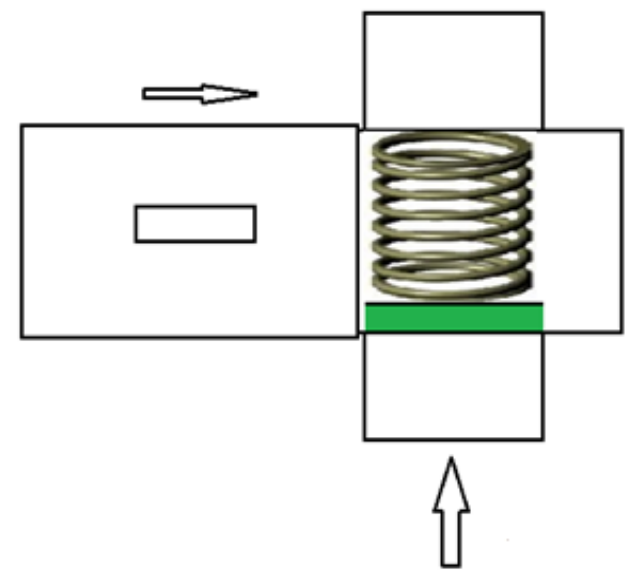

Fig.3 Activated carbon barrel tectonic map

\section{Research and development of real objects}

The manufacture of activated carbon barrel. We selected white steel making charcoal bucket shell. In view of the actual weight and rationality, the length is $200 \mathrm{~mm}$, slightly less than now rural household's chimney. Outside Diameter is about $90 \mathrm{~mm}$ and internal diameter is $50 \mathrm{~mm}$. In order to 
ensure the flue gas pass through device smoothly, the pore size is $4 \mathrm{~mm}$.

Sliding lid box. According to the relevant literature ${ }^{[2]}$, we know that the activated carbons in the wet state that removing dusts efficiency are the highest, we use the method of artificial water spray to increase the humidity of activated carbon. According to the working life of activated carbons, they don't need to be replaced frequently in use process. Flue gas will bring water to the entire device which achieved humidifying effect. The modification of the experiment has big effect.

The overall physical diagram of the device is as the following picture:

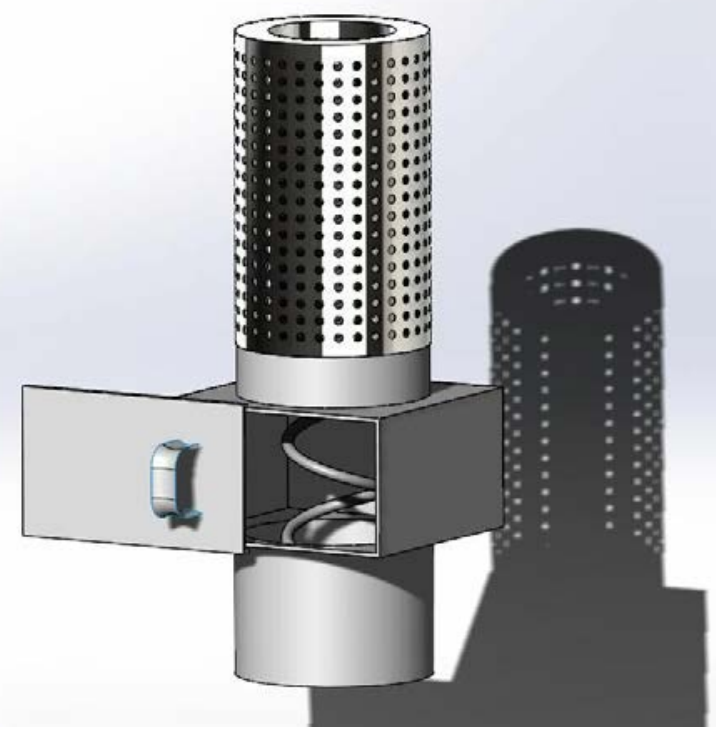

Fig.4 The stereogram of device

\section{Experimental testing and data analysis}

Analysis and concentration of flue gas and dust. We used flue gas concentration analysis instrument to measure the concentrations of the flue gas. Smoke concentration before and after are shown as fig.5:

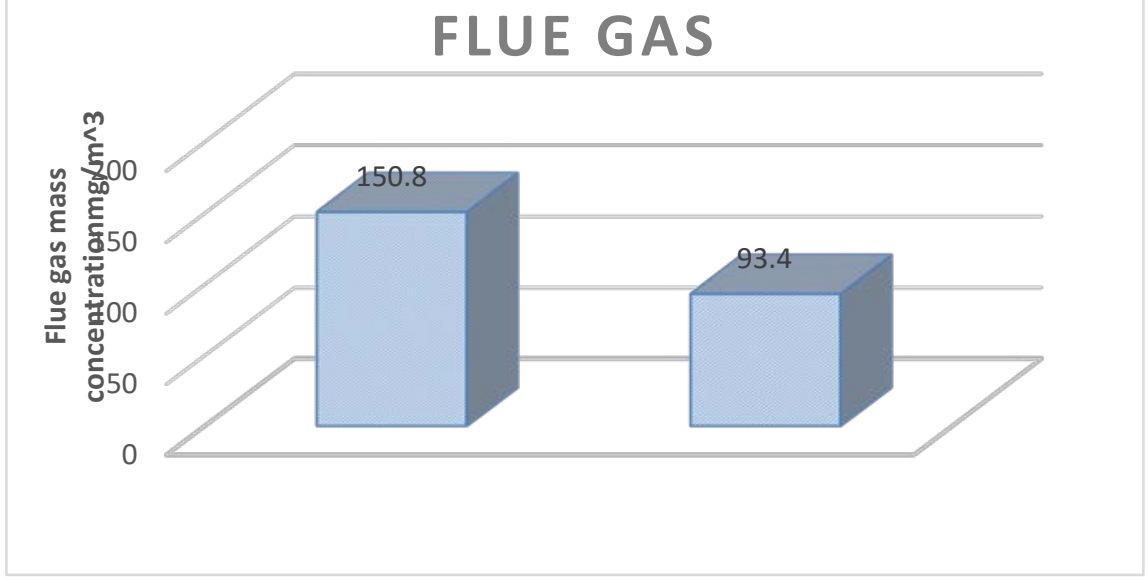

Fig.5 Flue gas concentration

We can find that the after we feed device, the smoke concentration is reduced about $57.4 \mathrm{mg} / \mathrm{m}^{3}$. Dust removal efficiency is arrived $w=1-\frac{93.4}{150.8}=38.06 \%$. It can be seen that our device have certain effect on remove dust.

Analysis of flue gas content. When the coal is completely burnt, the flue gas contains the following components: $\mathrm{CO}_{2}, \mathrm{SO}_{2}, \mathrm{H}_{2} \mathrm{O}$ and so on. We use flue gas comprehensive analyzer to measure. By reading the gas analyzer, we got the change of $\mathrm{CO}_{2}$ and $\mathrm{SO}_{2}$. 


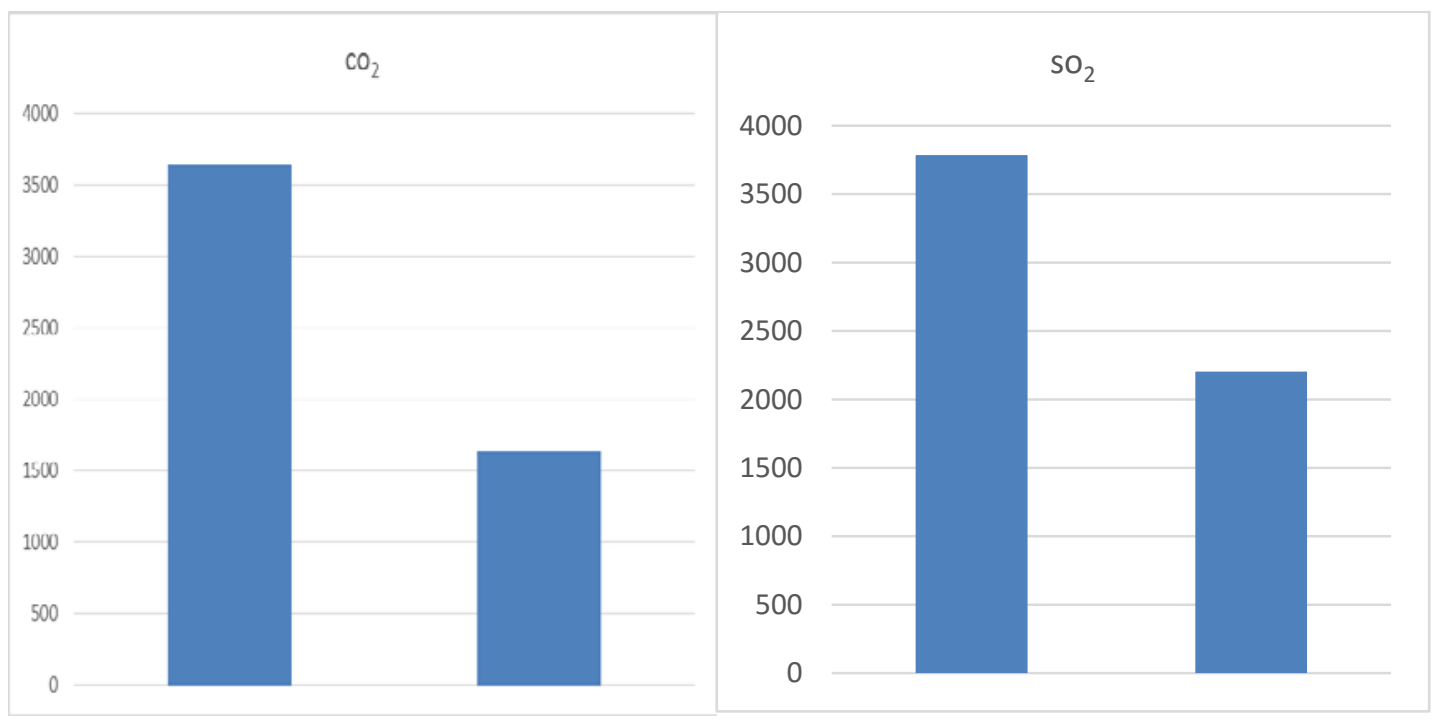

Fig.6 The change of $\mathrm{CO}_{2}$ and $\mathrm{SO}_{2}$

\section{Conclusions}

In order to reduce the dust emission the pollution of the atmosphere in the countryside, reduce greenhouse gas emissions, the project designed dust removal device for households with coal-fired stove. The project basically completed the intended target and developed a set of smoke and dust removal device. The flue gas particulate matter, as well as carbon dioxide and sulfur dioxide absorption has played a good effect. The device is suitable for batch production which can be widely applied.

\section{Reference}

[1] Angelos M. Environmental Impacts of Coal Combustion Residues[J]. Journal of Environmental Quality, 2006, 46(46):1018-22.

[2] Figueiredo J L, Pereira M F R, Freitas M M A, et al. Modification of the surface chemistry of activated carbons[J]. Carbon, 1999, 37(9):1379-1389. 